\title{
Integrating human and natural systems sustainably: emergy evaluation and visualization of the Abruzzo Region
}

\author{
R. M. Pulselli ${ }^{1}$, P. Romano ${ }^{1}$, D. Bogunovich ${ }^{2}$ \& F. M. Pulselli ${ }^{1}$ \\ ${ }^{1}$ Department of Chemistry, University of Siena, Italy \\ ${ }^{2}$ School of Architecture and Landscape Architecture, \\ Unitec, New Zealand
}

\begin{abstract}
This paper presents an environmental accounting method, based on Odum's systems theory. So-called emergy analysis (spelled with an M) was here applied for evaluating sustainability of the Abruzzo Region, a large area in the middle of Italy along east coast. This study attempts to answer questions concerning: globalization (strong competition among regional and national systems, outsourcing of productive activities), energy (growth of consumptions, cost and lack of resources), territorial disequilibrium (concentration of activities and environmental impacts) and use of resources (renewable and non renewable).

The aim of this research is to study a territorial system and to verify potentiality and contribution that this environmental accounting technique provides to manage and to program the future development. In particular this study aims to understand the functioning of a region based on the analysis of stocks and flows of energy and matter inside the examined area, investigating their spatial distribution and their relationships with geo-morphological structure of territory. This study further evaluates the use of local resources and aims to understand the relationships among the different parts of a territorial systems, their level of autonomy in terms of resource use and their effective spatial boundaries, which usually do not correspond to the administrative limits. The study also attempts to present the evaluation in an easily comprehensible graphic manner as digital maps.
\end{abstract}

Keywords: environmental accounting, urban metabolism, emergy evaluation, spatial patterns, emergy geography. 


\section{Introduction}

Nowadays, there are types of "magnitudes" that cannot be measured. The quantities of processes of production, economic systems and cities elude our understanding. Although they were built by human hand, they have dimensions that seem to exceed all norms and overwhelm human beings. These and the processes that feed them, the inputs and outputs, the natural resources they consume, the entropy dissipated, cannot be readily measured. Although we have many types of measures, they do not fully answer our questions [1].

A major aspect of recent research has been the development and testing of environmental accounting methods and associated sustainability indicators. There are many possible indicators. Here we consider the concept of emergy, developed by Howard Odum at the University of Florida, based on an energy and material flow inventory.

Emergy evaluation is a method of environmental accounting that measures stored energy or rather the energy used (and memorized) in all phases of the process of production of a good. It considers the action of nature that generated the primary resources, endeavouring to quantify the work of the environment in energy terms. This is why eMergy is also known as a sort of energy memory, a definition formulated by David M. Scienceman [2], or the memory of all the energy needed to support a process or system. It is the overall energy upstream of a process, including the man-made part (fuel, electricity, materials, machinery, labour ...) and the natural part (solar energy, sedimentary cycle, geothermal heat ...) that feeds the primary processes on which all production cycles are based. In other words, emergy analysis aims to define the environmental cost of goods of different categories and to estimate the quantity of work done by nature to provide the resources used in production.

Odum sought a logical and coherent answer to the dilemma of how to measure the natural processes that produced the wood of a tree, the stone obtained from a quarry and oil extracted from the depths of the Earth [1].

In Odum's theory, solar energy is the common denominator through which the "real value" of every natural resource can be estimated, since everything has an energy content and requires flows of energy and matter to come into being. The sun is the prime mover that provided the energy necessary to form trees, rock and oil.

According to Odum [3]: "Quantitative understanding of the relationships between human-dominated systems and the biosphere is the realm of emergy analysis". He conceived emergy as an instrument to assign an "environmental value" to resources in proportion to the "dimension" of the processes producing man-made and natural systems. Different inputs and outputs of systems and processes (fuels, energy, materials, food ...) may be expressed in terms of solar energy. By definition [4,5], emergy is the quantity of solar energy equivalent needed directly or indirectly to obtain a product by a process or to renew a resource that has been consumed. The units of emergy are solar emergy joules or solar emjoules (sej). 
By definition, the emergy $E m_{k}$ of an output flow $k$ of a process is:

$$
E m_{k}=\sum_{i=1}^{n} E n_{i} \times E U_{i}
$$

where $E n_{i}$ is the effective energy content of the $i$ th input and $\mathrm{EU}_{\mathrm{i}}$ is the emergy per unit of the $i$ th input. The emergy per unit of inputs is in turn derived from a previous process.

In emergy assessment, certain resources have a higher specific weight than others, but an overall balance is obtained by assessing all the forces that sustain the system and that the system in turn exerts on the environment. The bigger the overall emergy flow needed to support a process generating a type of energy or a material, the greater the quantity of solar energy it "consumes", or the greater the past and present environmental cost to obtain it or regenerate it [6].

Based on these criteria, emergy analysis allowed us to identify and quantify relations entertained by a local context with other systems on a global scale and with local resources. How much and what kind of energy and material reach the region? How are flows of local resources drawn from stocks? How are they distributed in space and with what intensity? The answer to these questions can provide a key for addressing practices of regional planning [1].

The present study consists of the following phases: first, understanding of the different components of territorial system (energy and material flow inventory); second, calculation process of emergy flows; finally, the analysis of outcomes plotted on maps, which outline the concentration of emergy flows in space and the main components (energy and matter), which feed the territory, otherwise invisible $[7,8]$ (except in the case of lights at night!).

\section{Outcomes from the emergy analysis: a case study}

An emergy analysis of the Abruzzo Region was conducted. The research project was commissioned by the regional administration, namely Direzione Parchi Territorio Ambiente Energia. The analysis considered the main flows in the various sectors, estimating the quantities of energy and matter used in the region in a year. The examined area has a surface of $10,788 \mathrm{Km}^{2}$. Once transformed into equivalent emergy quantities, emergy flows were classified into different categories (renewable and non renewable; local and external) as shown in Table 1.

Total emergy input ( $\mathrm{U}=7,52 \mathrm{E}+22$ sej) was partly (69\%) due to imported goods (F) acquired on the market, such as fuel $(\mathrm{F} 1=1,30 \mathrm{E}+22 \mathrm{sej})$, food and materials $(\mathrm{F} 2=3,90 \mathrm{E}+22 \mathrm{sej})$, partly $(29 \%)$ due to resources withdrawn from local stocks, especially quarried material $(\mathrm{N}=1,93 \mathrm{E}+22 \mathrm{sej})$, and the remaining minor part (2\%) was from renewable natural resources $(\mathrm{R}=1,41 \mathrm{E}+21 \mathrm{sej})$.

In the following phase the analysis considered two emergy based indicators: empower density (ED) and environmental loading ratio (ELR). The first one, corresponding to the ratio between the total emergy (U) and the surface of the examined area, is a measure of impacts of human activities on the territory. This allowed us to distinguish different parts in the region with different functions and 
vocations. The second one, corresponding to the ratio between non-renewable resources, both local and purchased $(\mathrm{N}+\mathrm{F})$, and local renewable resources $(\mathrm{R})$, pointed out the relative significance of renewables in sustaining local activities with respect to non-renewables. This can be taken to be a very direct and reliable measure of sustainability. Results were shown in Table 2.

Table 1: $\quad$ Results from the emergy analysis of the Region Abruzzo.

\begin{tabular}{|cccccccc|}
\hline EMERGY & $\mathrm{R}$ & $\mathrm{N}$ & $\mathrm{L}=\mathrm{R}+\mathrm{N}$ & $\mathrm{F} 1$ & $\mathrm{~F} 2$ & $\mathrm{~F}=\mathrm{F} 1+\mathrm{F} 2$ & $\mathbf{U}=\mathbf{L}+\mathbf{F}$ \\
\hline UNIT & sej & sej & sej & sej & sej & sej & sej \\
\hline REGION & $1,41 \mathrm{E}+21$ & $2,18 \mathrm{E}+22$ & $2,32 \mathrm{E}+22$ & $1,30 \mathrm{E}+22$ & $3,90 \mathrm{E}+22$ & $5,20 \mathrm{E}+22$ & $\mathbf{7 , 5 2} \mathbf{E}+\mathbf{2 2}$ \\
\hline & $2 \%$ & $29 \%$ & $\mathbf{3 1 \%}$ & $17 \%$ & $52 \%$ & $\mathbf{6 9 \%}$ & $\mathbf{1 0 0} \%$ \\
\hline
\end{tabular}

Table 2: $\quad$ Sustainability indicators in Region Abruzzo.

\begin{tabular}{|cccc|}
\hline INDICATORS & & Region Abruzzo & unit \\
\hline ED (empower density) & U/area & 7 E+15 & sej/mq \\
\hline ELR (environmental loading ratio) & N $+\mathrm{F} / \mathrm{R}$ & 52 & - \\
\hline
\end{tabular}

\section{An emergy based geography}

Specific assessment of local areas (305 municipalities) in the Region made it possible to discover the "geography" of the Region with respect to use of environmental resources. Different intensities of inputs showed a nonhomogeneous distribution over the region. This reflected the different intensities of direct or indirect exploitation of environmental resources going on in the various local contexts. Figure 1 is a map of the Region Abruzzo showing the intensity of emergy flows.

The "emergy geography" reflected the use of environmental resources in the different areas, revealing a general organizational scheme. Areas with higher and lower intensity had very different vocations and developmental perspectives. Moreover, similarities were found between patterns of emergy flows and the physical disposal of settlements and infrastructure in the examined territory.

High intensity emergy flows were detected mostly in the area along the seacoast and in the valleys in the inland, including towns and other particularly energy-hungry activities (high consumption of energy or import of large quantities of material for processes) such as industrial districts. In this area, the empower density (ED) corresponds to $18 \mathrm{E}+15 \mathrm{sej}$, about three times the regional value $(7 \mathrm{E}+15)$. This is due to the concentration in this area of transformation processes, a high population density and residential areas. Extraction of primary material, such as quarries, were shown in the map by black spots.

Areas with lower intensity show a nature conservation vocation, generally with natural parks. These formed a homogeneous area with low population density and little agriculture. 


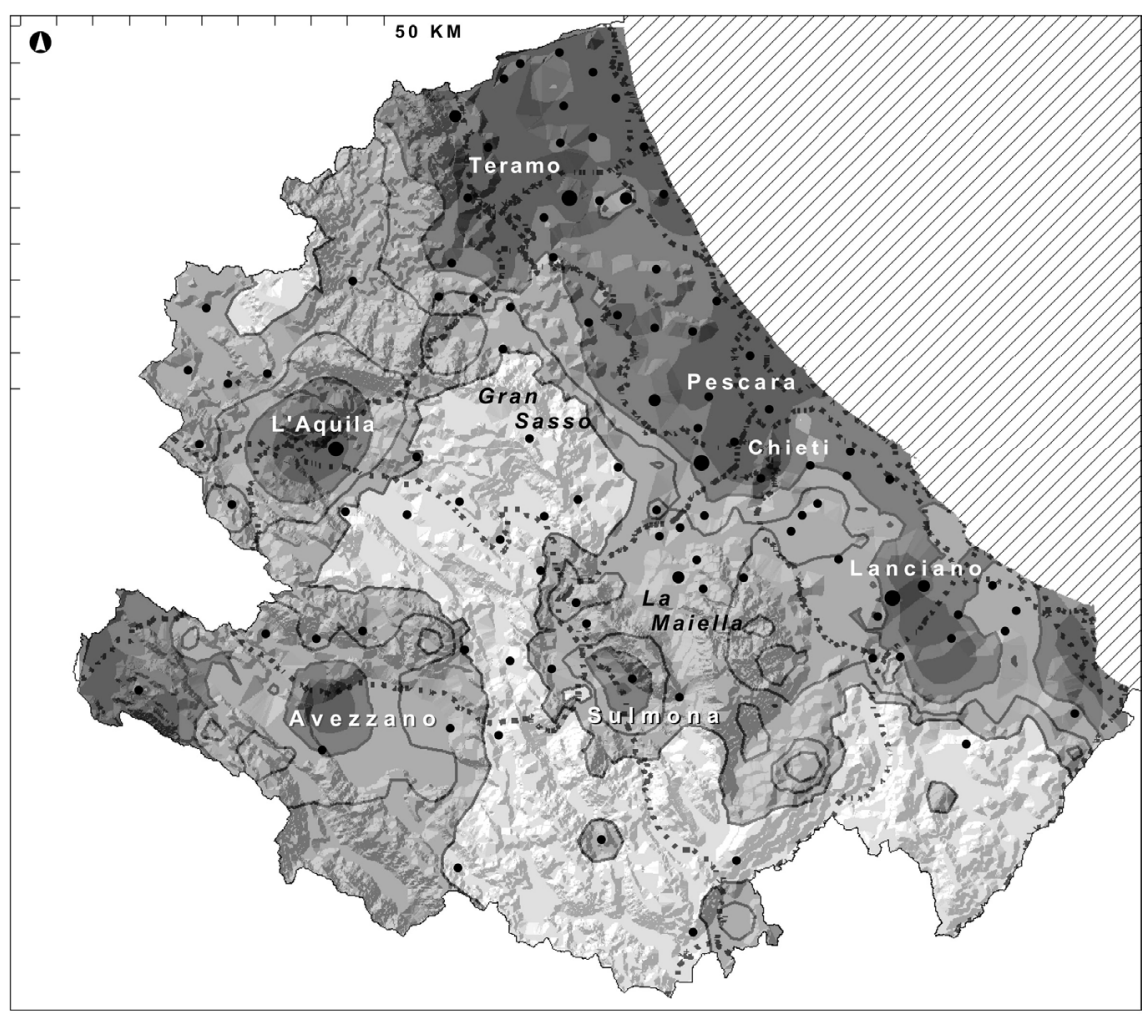

Figure 1: Map of intensity of emergy flows in the Region Abruzzo. The black spots refer to extraction activity.

Finally, areas with middle intensity correspond to the zone that connects areas with high intensity emergy flows, in particular between the coast (Teramo, Pescara, Chieti) and the inland (L'Aquila, Avezzano, Sulmona).

\section{Conclusions}

This research showed the application of an environmental accounting method, namely emergy evaluation, to evaluate the level of sustainability of a territorial system, the Region Abruzzo (Italy), and to assess the use of resources supporting the economic and social system and living standards of people. In particular this study highlighted: first, kinds of resources used in the territory and their origin (renewable or non renewable, local or external); second, localization and concentration, in terms of intensity, of material and energy flows inside the region (areas with high or low intensity). The analysis and quantification of these phenomena together with the outcomes obtained by the calculation of emergy based synthetic indicators (empower density and environmental loading ratio), allowed us to understand the thermodynamic performance of productive, urban and environmental systems in the region. 
In particular, "emergy geography" was the innovative aspect of this research. The application of geographical information system tools allowed to produce "smart maps", able to describe the main material and energy flows and their varied concentration inside the territory. The cartographic approach thus made visible what usually is not visible - the metabolism of the examined region. The outcomes in the form of maps enabled us to highlight the presence of three different zones, whose boundaries, most often ignoring the artificial administrative boundaries, provide a kind of representation of the real functioning of the regional system. The new revealed geography together with the specific vocations of each part of territory, their potentiality and criticality, provide a fuller whole picture of the territorial system and thus better inform local administrations. The potential of this methodology to inform the practice of urban planning and environmental management in the direction of higher sustainability is significant.

\section{References}

[1] Pulselli, R.M. and Tiezzi, E., City Out of Chaos. Urban Self-organization and Sustainability, WITpress, Southampton, 176 pp., 2009.

[2] D.M., Scienceman, Energy and emergy. Environmental Economics; the Analysis of a Major Interface, eds. G. Pillet \& T. Murota Roland Leimgruber, Geneva, pp. 257-276, 1987.

[3] Odum, H.T., Self organization, transformity and information. Science, 242, pp. 1132-1139, 1988.

[4] Odum, H.T., Environment, Power and Society, Wiley, New York, 1971.

[5] Odum, H.T., Environmental Accounting: Emergy and Environmental Decision Making, Wiley, New York, 1996.

[6] Pulselli, F.M., Bastianoni, S., Marchettini, N. and Tiezzi, E., The Road to Sustainability. GDP and future Generations, WITpress, Southampton, pp. 197, 2008.

[7] Pulselli, R.M., Rustici, M. and Marchettini, N., An integrated holistic framework for regional studies: emergy based spatial analysis of the province of Cagliari. Environmental Monitoring and Assessment, 133, pp. 113, 2007.

[8] Pulselli, R.M., Pulselli, F.M. and Rustici, M., The emergy accounting of the Province of Siena: towards a thermodynamic geography for regional studies. Journal of Environmental Management, 86, pp. 342-353, 2008. 